\title{
Influence of Metallic Sodium on Repair Weldability for Type 316FR Stainless Steel
}

\author{
Eun-Joon Chun*, ${ }^{*}$ Su-Jin Lee*, Jeong Suh*, Ju-Seung Lee**, Namhyun Kang*** \\ and Kazuyoshi Saida**** \\ *Busan Laser Application Support Center, Korea Institute of Machinery and Materials (KIMM), \\ Busan 46744, Korea \\ **3rd Land System Team, Defense Agency for Technology and Quality, Gyeongsangnam-do 51474, Korea \\ ***Department of Materials Science and Engineering, Pusan National University, Busan 46241, Korea \\ ****Division of Materials and Manufacturing Science, Osaka University, Osaka 565-0871, Japan \\ †Corresponding author : eunjoonchun@kimm.re.kr \\ (Received October 12, 2016 ; Revised November 28, 2016 ; Accepted February 1, 2017)
}

\begin{abstract}
The effect of residual metallic sodium on the solidification cracking susceptibility of type 316FR stainless steel was investigated via transverse-Varestraint tests. And a solidification brittle temperature range (BTR) of type 316FR stainless steel was $37 \mathrm{~K}$. However, the BTR expanded from 37 to $67 \mathrm{~K}$, as the amount of metallic sodium at the specimen surface increased from 0 to $7.99 \mathrm{mg} / \mathrm{cm}^{2}$. Microstructural observation of the weld metal suggested that metallic sodium existed in the weld metal, including in the cell boundaries, during welding solidification. Thermodynamic calculations suggested that sodium expanded the temperature range of solidliquid coexistence during welding solidification of the steel weld metal. Therefore, the increased solidification cracking susceptibility (i.e., expansion of the BTR) in the residual sodium environment was attributed to enhanced segregation of sodium during the welding solidification; this segregation, in turn, resulted in an expanded temperature range of solid-liquid coexistence.
\end{abstract}

Key Words : Welding, Solidification cracking susceptibility, Varestraint test, Metallic sodium

\section{Introduction}

Securing an efficient energy source that will contribute to a reduction in global warming and replace gradually diminishing fossil fuels, has received significant attention recently. Nuclear power generation has received increasing attention as a possible replacement, owing to its stable and efficient energy supply, despite radioactivity and nuclear waste concerns. Of the various types of nuclear power generation, the fast breeder reactor (FBR, using fast neutrons that breed Plutonium239 from Uranium-238) is considered the most advanced owing to its more efficient use of fuel. Type 316FR stainless steel modified based on type 316L steel, which has better creep fatigue properties than those of other austenitic stainless steels, is a promising structural material for the primary coolant circuit in next-generation commercial FBR plants ${ }^{1,2)}$. However, when FBR plants have been in operation for a long time (max. about 40 years), then components suffering from the effects of sigma phase embrittlement, creep fatigue or corrosion in a liquid sodium environment will require essential maintenance, which typically involves welding ${ }^{2,3)}$.

Prior to establishing repair-welding processes for aged FBR plants, the typical differences between an FBR and other general types of reactors (e.g., light water-cooled reactors) must be understood. Firstly, owing to its high thermal conductivity, an FBR uses molten sodium metal as a coolant instead of water. Secondly, compared to other reactors, an FBR operates at higher temperatures of 773-823 K, owing to its high degree of heat generation. After long-term service exposure, however, corrosion stemming from the flow of liquid sodium at high service temperatures, damages the surface layers of the structural materials ${ }^{3,4}$. Consequently, overlay welding is considered a promising candidate for the repair welding 
of aged FBR plants.

Although liquid sodium is drained from the sodium loop prior to repair welding, a small amount of metallic sodium may persist at the surface of the structural material; i.e., repair welding would be performed in a metallic sodium environment. As such, determining the effect of residual metallic sodium on the repair-weldability is essential. During any welding process for austenitic stainless steel, special attention needs to be paid to the alloy's weldability under the viewpoint of hot cracking, such as solidification, liquation and ductility-dip cracks ${ }^{5,6)}$. Even though, liquation and ductility-dip cracks have been confirmed when the repair welding of aged stainless steels (for HP-modified stainless steel), one of the crucial cracks has been regarded as solidification crack for austenitic stainless stee ${ }^{15-21)}$. However, the effect of sodium on this susceptibility has not been quantitatively studied. The objective of the present study, therefore, is to examine the changes in the solidification cracking susceptibility of a type 316FR stainless steel in a metallic sodium environment. This study is performed as part of a larger goal of establishing welding repair processes for next- generation FBR plants.

\section{Materials and experimental procedures}

\subsection{Materials}

The material selected in this study is a filler metal for type 316FR stainless steel, whose composition lies within the compositional range of the steel ${ }^{2}$. The chemical composition (mass\%) of the steel is shown in Table 1 . This steel was hot-rolled to a $100 \mathrm{~mm}$ (length) $\times 50 \mathrm{~mm}$ (width) $\times 3$ or $5 \mathrm{~mm}$ (thickness) plate and solution- treated at $1423 \mathrm{~K}$ for $30 \mathrm{~min}$ for full austenization. The corresponding $\mathrm{Cr}_{\mathrm{eq}} / \mathrm{Ni}_{\mathrm{eq}}$ value indicates that primary austenite and secondary $\delta$-ferrite (AF) were formed during solidification of the stee ${ }^{6,7)}$.

\subsection{Immersion test in liquid sodium}

To simulate a metallic sodium environment, an immersion test was performed in a liquid sodium pool. The plate was polished with eight conditions, each having a different roughness, in order to vary the amount of sodium at the specimen surface. Fig. 1 shows the procedures followed for the liquid sodium immersion test. The prepared specimens were connected by a wire, immersed in the sodium pool (in Fig. 1(a)), and the test was performed at $673 \mathrm{~K}$ for $640 \mathrm{~min}$. As Fig. 1(b) shows, the sodium was uniformly distributed at the surface of the specimen. The amount of adhered metallic sodium, which varied from 0.092 to $0.940 \mathrm{~g}$ depending on the roughness of the specimens, was measured using an electronic scale. After the test, each immersed specimen was stored in a desiccator (Fig. 1(c)) under argon

Table 1 Chemical composition of the steel used (mass $\%$ )

\begin{tabular}{|c|c|c|c|c|c|c|c|c|c|c|}
\hline & $\mathrm{C}$ & $\mathrm{S}$ & $\mathrm{P}$ & $\mathrm{Cr}$ & $\mathrm{Ni}$ & $\mathrm{Mo}$ & $\mathrm{Si}$ & $\mathrm{Mn}$ & $\mathrm{N}$ & $\mathrm{Fe}$ \\
\hline $\begin{array}{c}\text { Type 316FR } \\
\text { stainless steel }\end{array}$ & 0.0085 & 0.0009 & 0.023 & 17.56 & 12.02 & 2.15 & 0.44 & 0.79 & 0.088 & Bal. \\
\hline
\end{tabular}

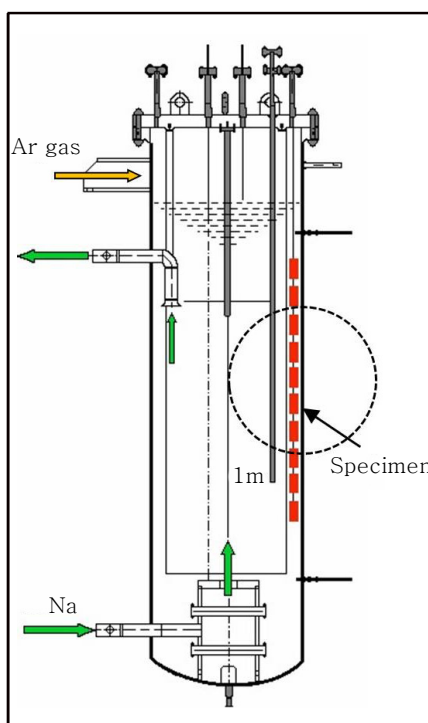

(a)

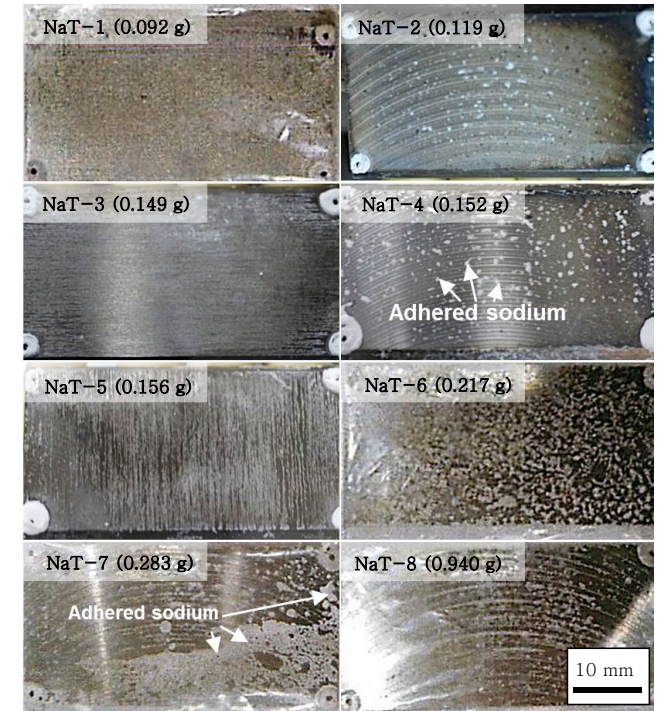

(b)

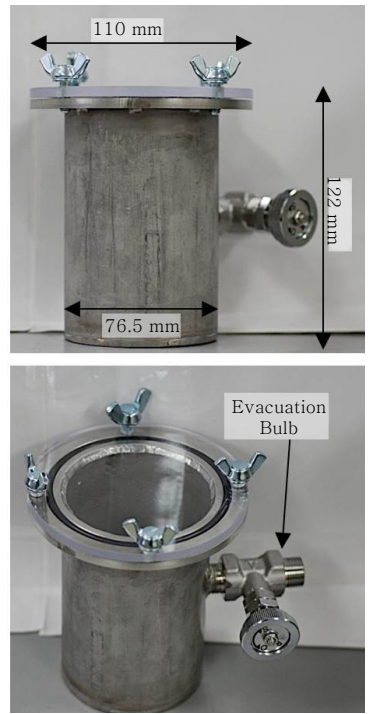

(c)

Fig. 1 Liquid sodium immersion test: (a) schematic of sodium pool, (b) appearance after immersion test, and (c) desiccator under argon atmosphere 
gas (99.99\% purity) atmosphere.

\subsection{Transverse-Varestraint test}

Transverse-Varestraint tests with gas tungsten arc (GTA) welding were performed in order to assess the solidification cracking susceptibility of the specimens. Fig. 2(a) shows a schematic of the workbench used in the test under the sodium environment. Owing to the strong reactivity of sodium, the workbench was shielded by argon gas (99.99\% purity) in a specially attached glove box, in which the overall procedures of the test were performed; the corresponding test parameters are listed in Table 2. The test was performed at a transverse welding speed of $1.67 \mathrm{~mm} / \mathrm{s}$ and a third-penetration bead was obtained by adjusting the arc current. Moreover, the augmented strain was varied from $0.25-1.64 \%$. Fig. 2(b) shows the dimensions of the test specimen used (thickness: 3 or $5 \mathrm{~mm}$ ) and the configuration of the bending block. The length of the transverse weld bead was adjusted to $40 \mathrm{~mm}$ and the temperature history during welding solidification was measured using a thermocouple $(\mathrm{Pt}-12 \% \mathrm{Rh} / \mathrm{Pt})$; this thermocouple was directly plunged into the weld pool during welding in order to obtain the range of cracking temperatures. The corresponding crack surface was examined using a scanning electron microscope (SEM).

\subsection{Microstructure observation of the weld metal}

To characterize the microstructure of the type 316FR steel weld metal, GTA bead-on-plate welding was performed on the prepared plates (without sodium immersion) under the same conditions (Table 2) used for
Table 2 Parameters used for the transverse-Varestraint test

\begin{tabular}{|c|c|}
\hline Test parameters & Values \\
\hline Electrode type & 2\% cerium-tungsten \\
\hline Arc current $(\mathrm{A})$ & 1.67 \\
\hline Arc voltage $(\mathrm{V})$ & 120 \\
\hline Arc length $(\mathrm{mm})$ & 2 \\
\hline Torch diameter $(\mathrm{mm})$ & 2 \\
\hline Torch direction & Perpendicular to specimen \\
\hline Shield gas & Argon $(99.99 \%$ purity) \\
\hline Gas flow rate $(1 / \mathrm{min})$ & 15 \\
\hline Augmented strain $(\%)$ & $0.25 \sim 1.64$ \\
\hline
\end{tabular}

transverse welding. The as-welded microstructures were characterized via electron backscatter diffraction (EBSD) after electrolytic etching with a $10 \%$ aqueous solution of $\mathrm{KOH}$ at room temperature.

\subsection{Preparation of the sodium-trapped weld metal}

Sodium-trapped weld metal was manufactured in order to clearly determine whether the weld metal contains sodium. The schematic in Fig. 3 shows the method used to prepare the weld metal. Pure sodium $(99.99 \%$ purity) was placed between the upper $(100 \times 5 \times 1 \mathrm{~mm})$ and lower plate $(100 \times 5 \times 9 \mathrm{~mm})$ of the steel (without sodium immersion). The specimen was then GTA bead-on-plate welded in the glove box (owing to the strong activity of sodium) using an arc current, arc voltage, and welding speed of $180 \mathrm{~A}, 14 \mathrm{~V}$ and $1.67 \mathrm{~mm} / \mathrm{s}$, respectively. In addition, an electron probe X-ray micro analyzer (EMPA) was used to determine the sodium

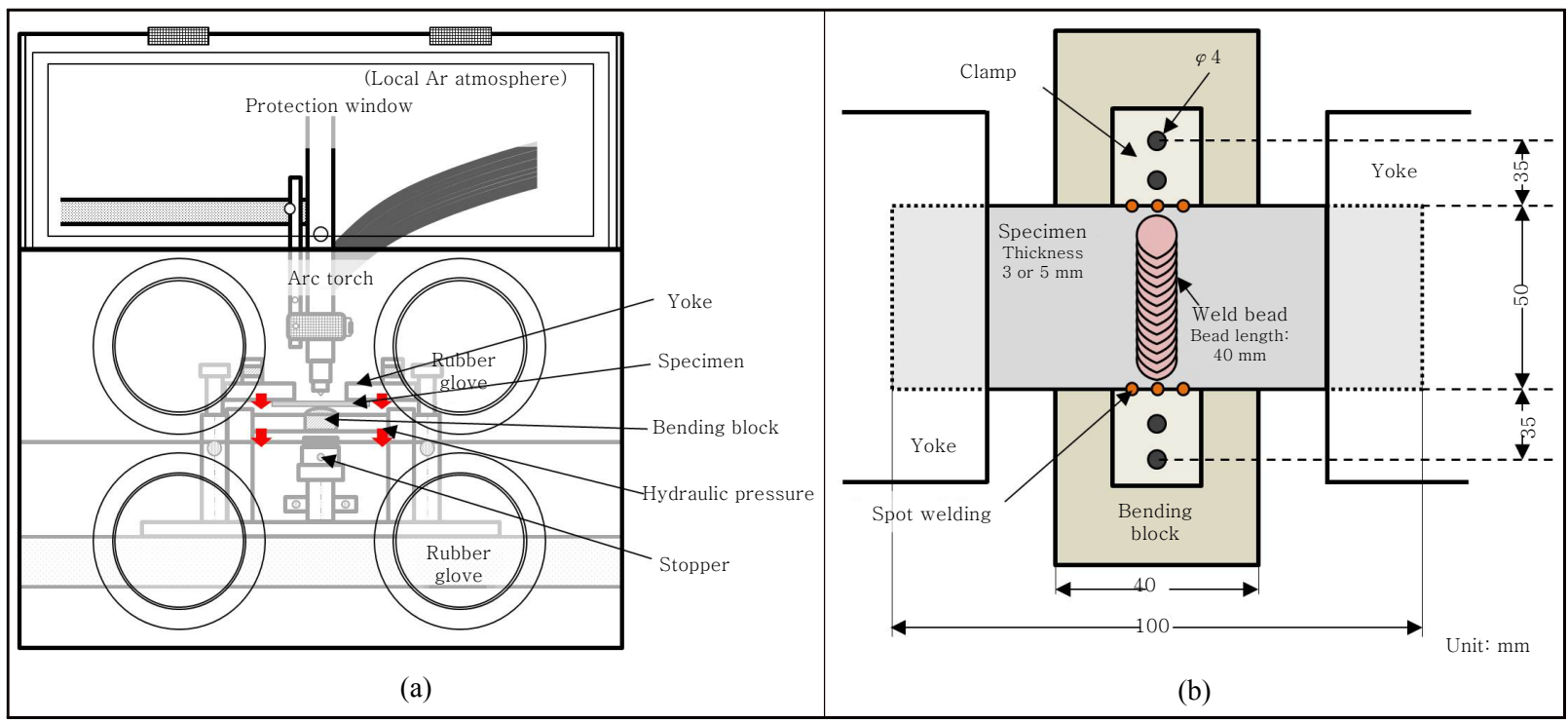

Fig. 2 Transverse-Varestraint test: (a) schematic of the workbench used in the test 


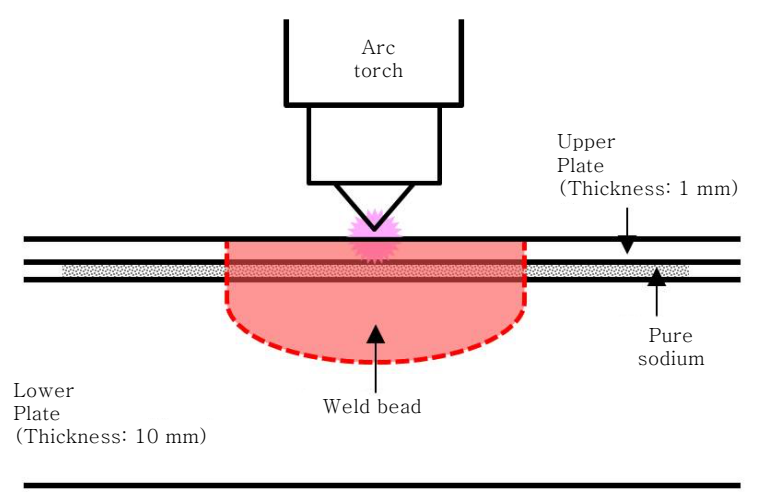

Fig. 3 Schematic of the GTA bead-on-plate welding for sodium-trapped specimen

content of the weld metal.

\section{Characterization of weld metal microstructure and solidification mode}

The cross-sectional view of the microstructure (Fig. 4(a)), as observed by EBSD, shows the cellular morphology that is typically associated with the current solidification behavior. The $\delta$-ferrite $(\delta)$ is located at the cell boundaries or triple points of austenite $(\gamma)$, is elongated or globular-shaped, and constitutes an average volume fraction of $3 \%$. In addition, it has been regarded that solidification mode of austenitic stainless steel can be characterized crystallographic orientation relationship between $\gamma$ and $\delta$. The inverse pole figure (IPF) map and the corresponding pole figures, Fig. 4(b) and (c), reveal the crystallographic orientation relationship between $\gamma$ and $\delta$. The pole figures show that these phases are related by a perfect parallel relationship, $<100>_{\gamma} / /$ $<100\rangle_{\delta}$, rather than the Kurdjumov-Sachs crystallo- graphic orientation relationship $\left(\{111\}_{\gamma} / /\{110\}_{\delta},<111>_{\gamma}\right.$ $\left./ /<110>_{\delta}\right)$. Similar relationships are confirmed at other locations of the weld bead. These characteristics are consistent with the AF mode that occurs with divorced eutectic solidification between $\gamma$ and $\delta$, and concur with the results of Inoue et al. ${ }^{22,23)}$ and Hashimoto et al. ${ }^{24}$, who determined the crystallographic orientation relationship in austenitic stainless steel weld metals.

\section{Solidification cracking susceptibility}

Fig. 5 shows the appearance and fracture surface resulting from the transverse-Varestraint test without sodium immersion (i.e., sodium-free condition). The fracture surface occurring on both the high (under the fusion line) and low temperature sides (away from the fusion line) had a dendritic structure with only a trace amount of melting. Microstructural observations of the crack surface revealed that this crack resulted possibly from solidification cracking. Similar morphologies were observed on the crack surfaces resulting from other strain conditions. However, ductility-dip and liquation cracks were not observed.

Fig. 6 summarizes the solidification cracking susceptibilities evaluated by using the crack length and number of cracks measured from SEM observations after the transverse-Varestraint test. Each bar represents a single crack, which is classified as either a crack, back-fill (filled with liquid from molten pool after crack initiation), or blank (crack-free). As the figure shows, the cracking susceptibility (number of cracks and crack length) increased with increasing applied strain. In addition, a solidification brittle temperature (BTR) of 37 $\mathrm{K}$ was obtained by using the maximum crack length and

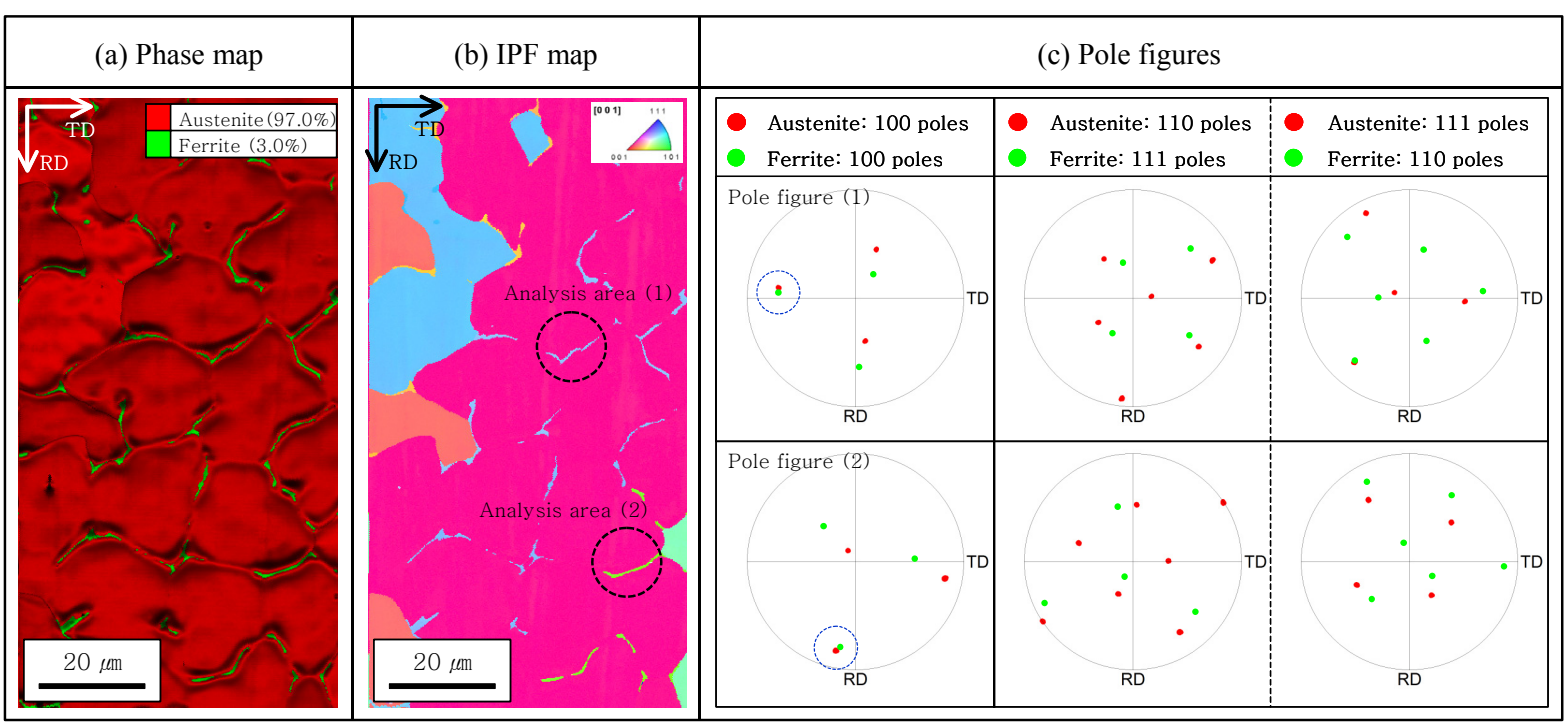

Fig. 4 EBSD analysis of the weld metal: (a) phase map, (b) IPF map, and (c) pole figures 


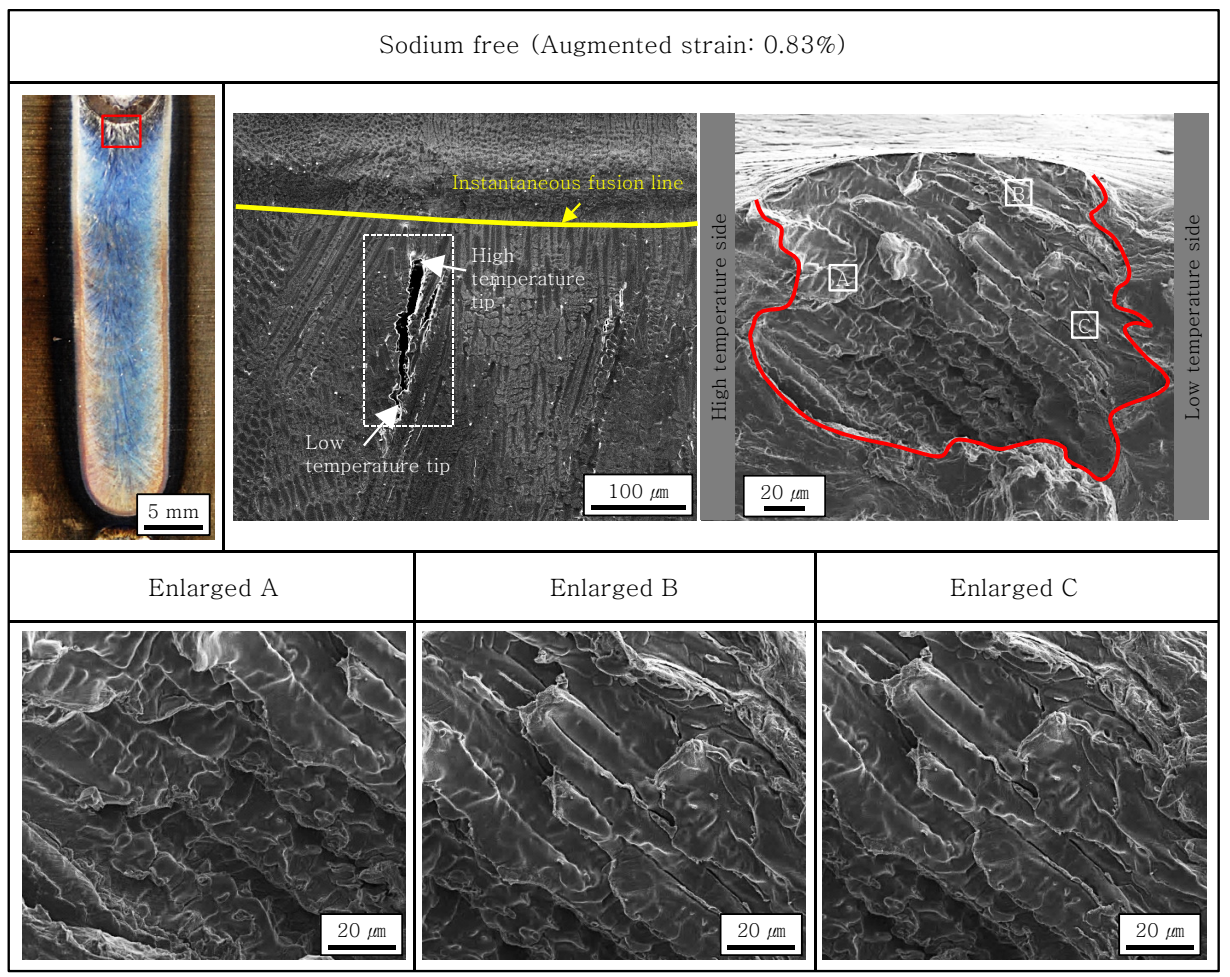

Fig. 5 Appearance and fracture surface, as observed by SEM, after the transverse-varestraint test (for sodium-free condition)

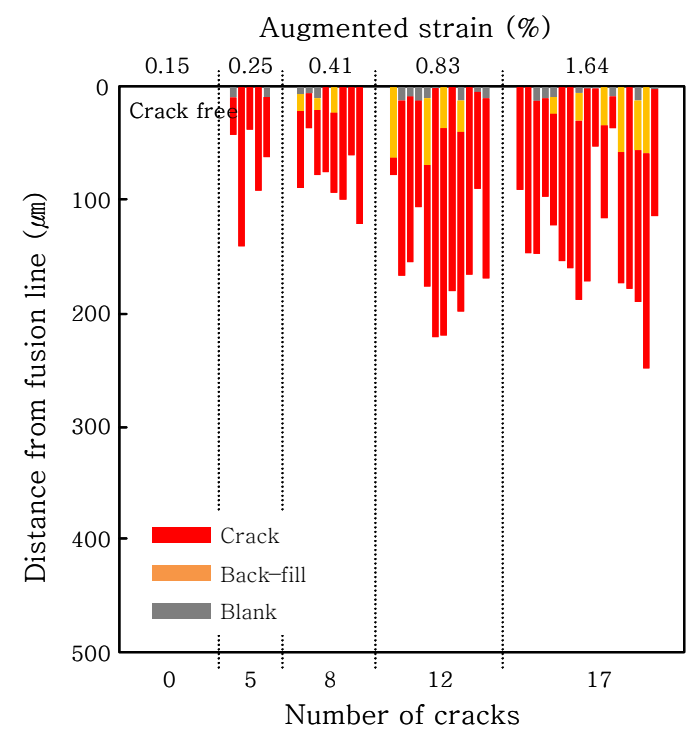

Fig. 6 Location and length of the solidification crack formed during the transverse-varestraint test

the cooling rate $(240 \mathrm{~K} / \mathrm{s})$ measured by the thermocouple. This BTR is shown in the ductility curve for solidification cracking (Fig. 7) of the type 316FR stainless steel.

\section{Effect of sodium on solidification cracking susceptibility}

Fig. 8 shows the typical appearance and fracture sur-

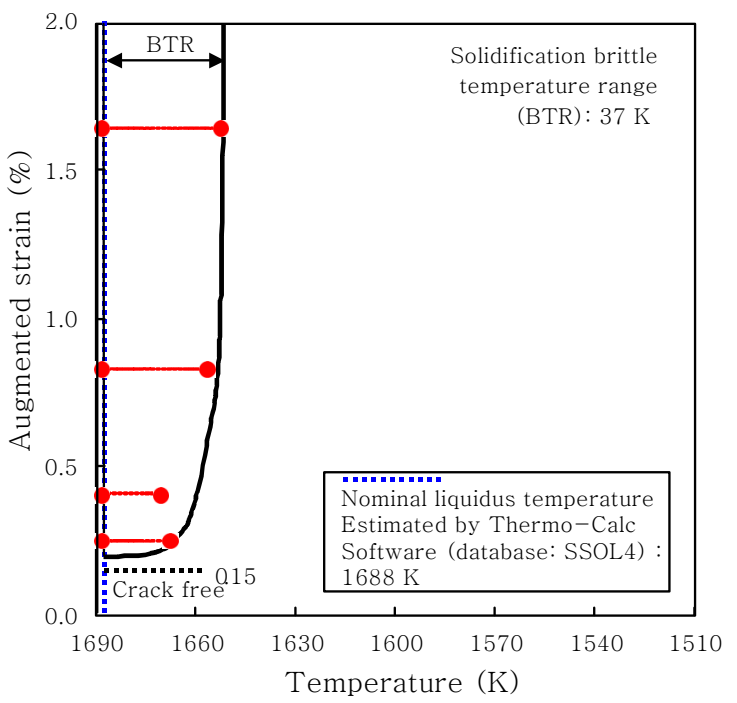

Fig. 7 High-temperature ductility curve of solidification cracking and BTR obtained from the transversevarestraint test

face resulting from the transverse-Varestraint test under metallic sodium environment (i.e., for sodium immersion specimen of NaT-7). Hot cracks could confirmed near the fusion line. The fracture surface of a crack indicates a totally dendritic structure with a trace of melting. In other words, the cracks formed by the transverse-Varestraint test under the metallic sodium environment can be regarded as solidification crack as similar with the sodium 


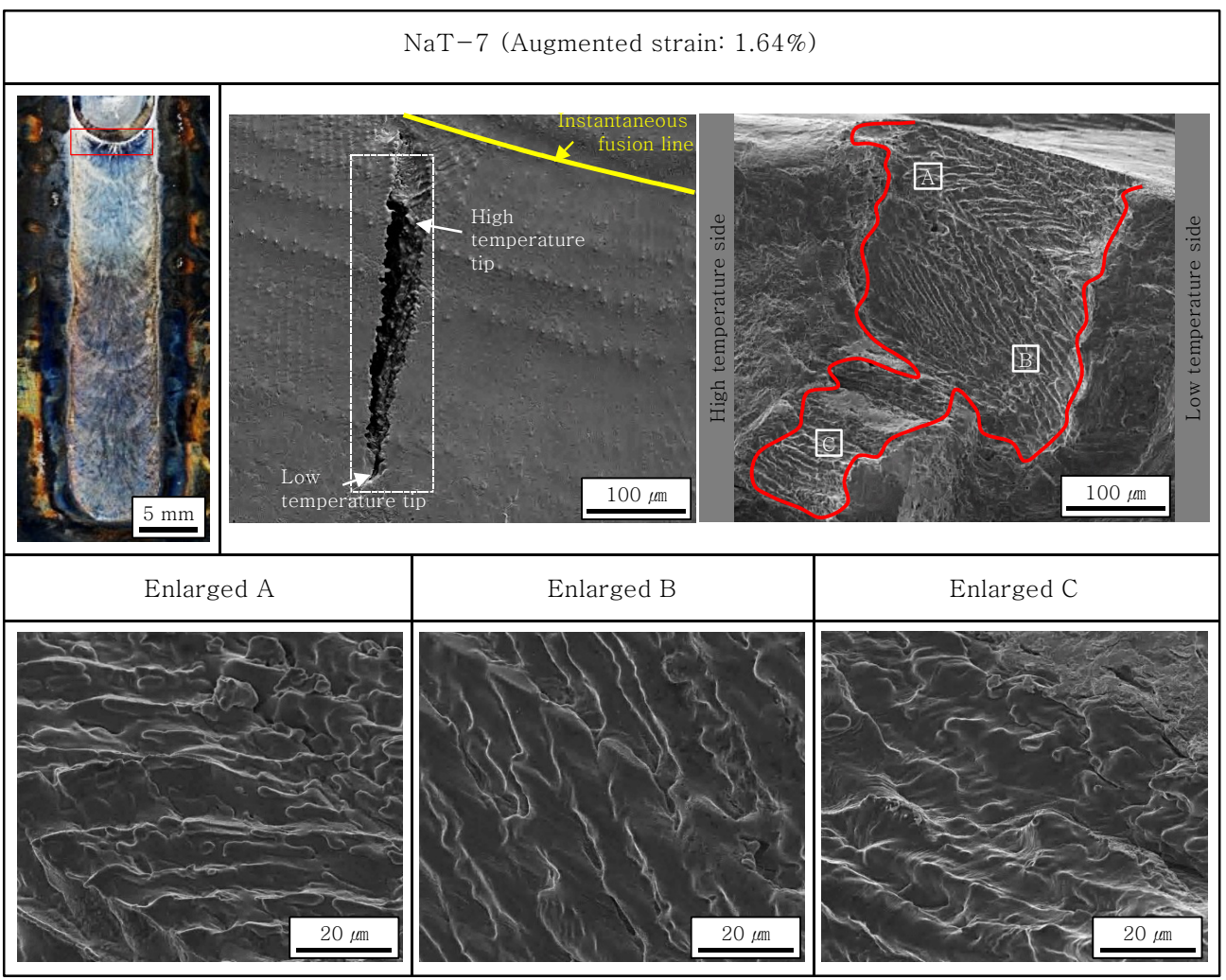

Fig. 8 Appearance and fracture surface, as observed by SEM, after the transverse-varestraint test (for specimens after sodium immersion test: NaT-7)

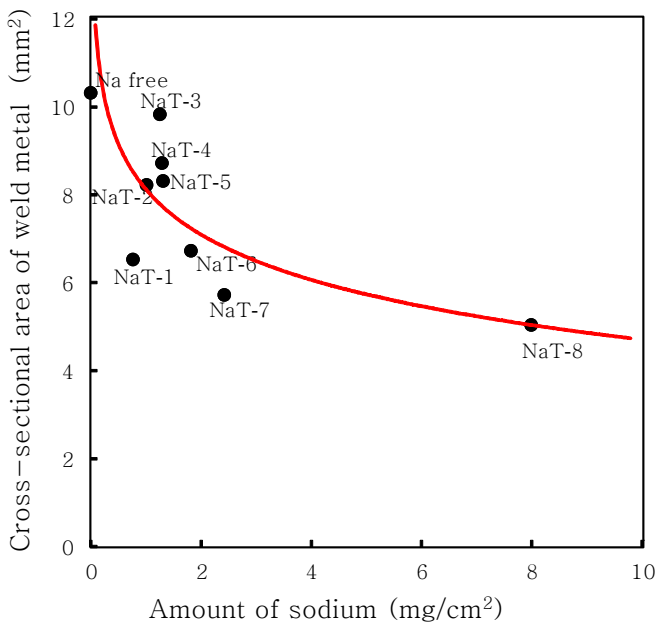

(a)

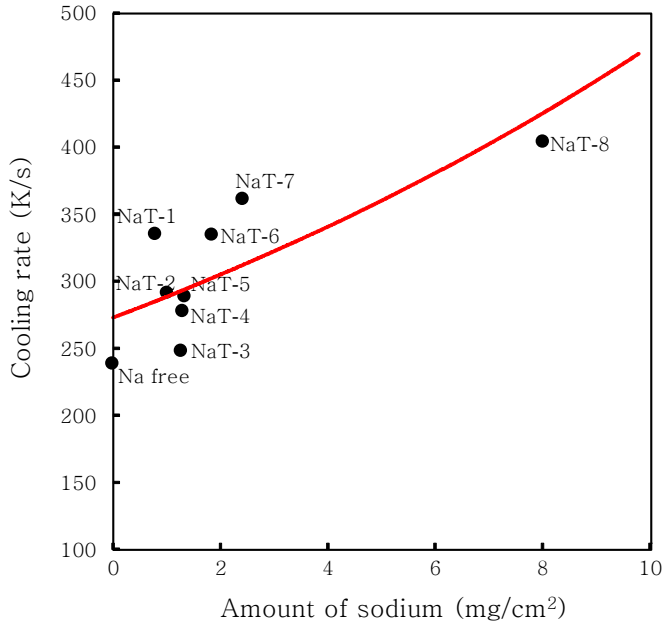

(b)

Fig. 9 Relationship between the amount of adhered sodium and the (a) cross-sectional area of the weld metal and (b) cooling rate

free specimen (in Fig. 5).

The BTR and high-temperature ductility curve for solidification cracking were determined for specimens with different amounts of adhered sodium (in Fig. 1(b)). A plot of the cross-sectional area of the weld metal as a function of the amount of adhered sodium shows that, in general, the former decreased with increasing values of the latter. In addition, Fig. 9(b) shows that the measured cooling rate varied from 239 to $405 \mathrm{~K} / \mathrm{s}$ with increasing amounts of sodium. Each cooling rate was applied to the corresponding immersed specimen in order to convert the temperature range of the solidification cracking. Moreover, for sodium amounts of $0-2.0 \mathrm{mg} / \mathrm{cm}^{2}$ (Fig. 10), the BTR expanded by $30 \mathrm{~K}$, from 37 to $67 \mathrm{~K}$, 


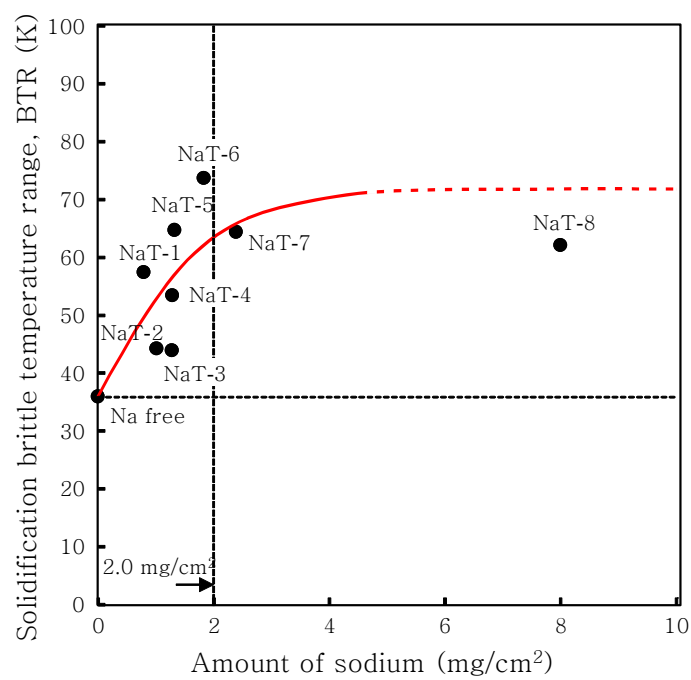

Fig. 10 Relationship between the amount of adhered sodium and the BTR but approximately remained constant thereafter.

\section{Mechanism of btr enlargement under sodium environment}

\subsection{Characterization of sodium content}

Fig. 11 shows an SEM image of the cross-section and the distribution of elements, as determined by EMPA, of the weld metal after the transverse-Varestraint test. Small amounts of sodium and slag (oxide composed of alloying elements) were detected in the sub-surface regions (Fig. 11(a)) of the specimen. The SEM and EPMA results (Fig. 11(b)) of a region just below the observation area in Fig. 11(a) reveal that the aforementioned oxide is also present at the cell boundaries; however, sodium was not clearly detected in this region. Namely, the results of the microstructural observation of the weld metal did not clearly confirm the presence of sodium during
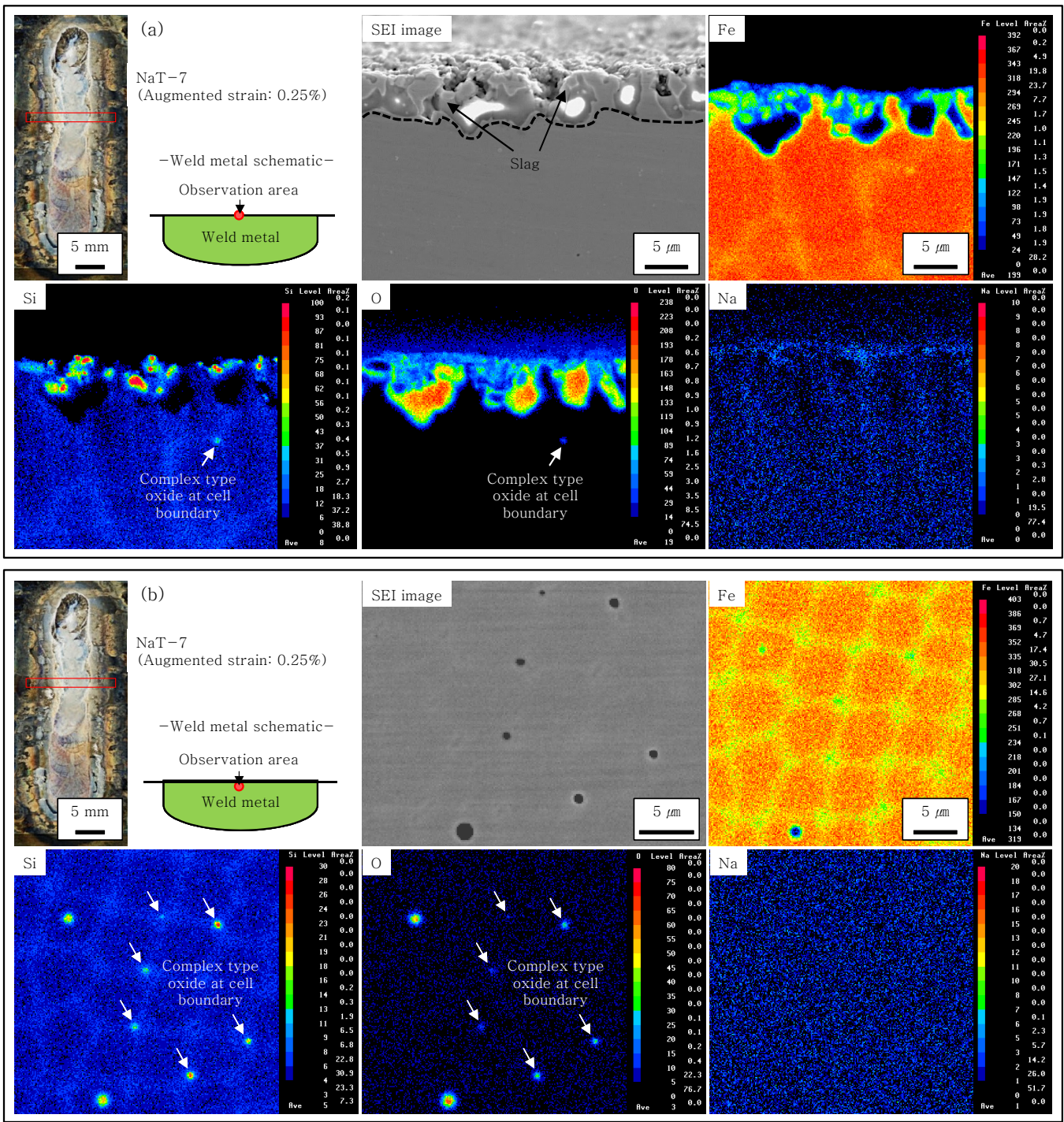

Fig. 11 EPMA analysis of the (a) sub-surface region and (b) bulk of the specimen after the transverse-varestraint test 
weld solidification. Moreover, although the Varestraint test was performed under argon atmosphere, the aforementioned oxide may be attributed to the characteristic ability of liquid sodium to easily form oxides under extremely low levels of oxygen ${ }^{25}$.

To determine whether sodium is present in the weld metal, Fig. 12 shows the corresponding cross-sectional microstructure of the sodium-trapped specimen (Fig. 3). Fig. 12(a) shows the SEM and EPMA results obtained from the sub-surface of the specimen. These results confirmed the presence of sodium in the slag layer, which is composed of oxide and alloying elements. Sodium was also mixed with the weld metal, thereby forming a mixing zone; i.e., an oxide composed of alloying elements. This mixing zone was easily distinguished from the weld metal and slag layer, owing to its distribution of chromium $(\mathrm{Cr})$, which differs markedly from those of the weld metal and the slag region. Furthermore, this observation suggests that the slight amount of sodium detected (Fig. 11(a)) after the transverse-Varestraint test stems from the formation of the slag and mixing zone. The SEM and EPMA results obtained from regions near the fusion line in the weld metal show that sodium was also present in the form of complex oxides, which consist of $\mathrm{Cr}$, nickel $(\mathrm{Ni})$, manganese $(\mathrm{Mn})$, and silicon (Si). Through these results, it was highly speculated that the sodium-free oxide located at the cell boundaries in Fig. 11(b) also related with sodium during weld solidification.
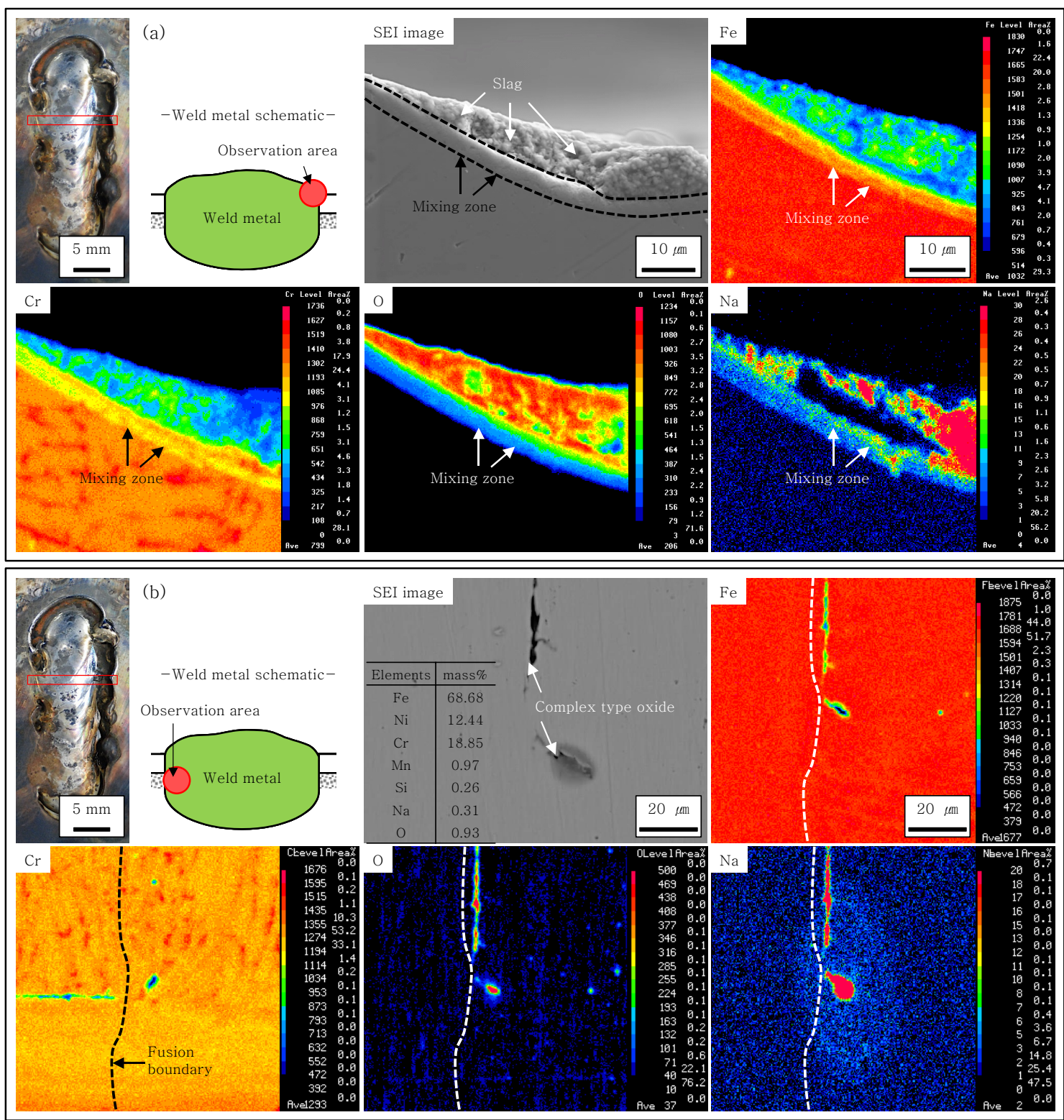

Fig. 12 EPMA analysis of (a) the sub-surface region and (b) near the fusion line after the GTA bead-on-plate welding described in Fig. 3 


\subsection{Theoretical calculation of solid/liquid coex- istence temperature range}

Numerous studies have reported that sulfur and phosphorous increase the susceptibility of stainless steels to solidification cracking; the BTR is especially affected by these elements. Sulfur and phosphorous segregate at the remaining liquid phase between the dendrites, thereby expanding the temperature range of solid/liquid coexistence during the welding solidification ${ }^{6-8,12,17-21)}$. Moreover, it is well-established that, in the equilibrium state of the material, this temperature range is almost directly proportional to the $\mathrm{BTR}^{6,7)}$. Sodium should mix with the weld metal during the welding solidification. As such, its effect on the temperature range of solid/liquid coexistence was investigated in order to determine the mechanism of BTR expansion in the sodium environment.

Fig. 13 shows the dependence of the equilibrium liquidus and solidus temperatures, as calculated from Thermocalc software (database: SSOL4), on the amount of sodium added to the steel. As the figure shows, the equilibrium liquidus and solidus temperatures decreased from 1688.8 to $1655.5 \mathrm{~K}$ and 1596.6 to $1538.3 \mathrm{~K}$, respectively, with increasing amounts ( 0 to 1 mass\%) of sodium. In other words, the temperature range of solid/ liquid coexistence in the equilibrium state expanded from 92.2 to 117.2 K ( $25 \mathrm{~K}$ broadening) with increasing amounts of sodium. The expansion of the BTR in the residual sodium environment was, therefore, attributed to the segregation of sodium during the welding solidification; this solidification, in turn, resulted in an expanded temperature range of solid/liquid coexistence.

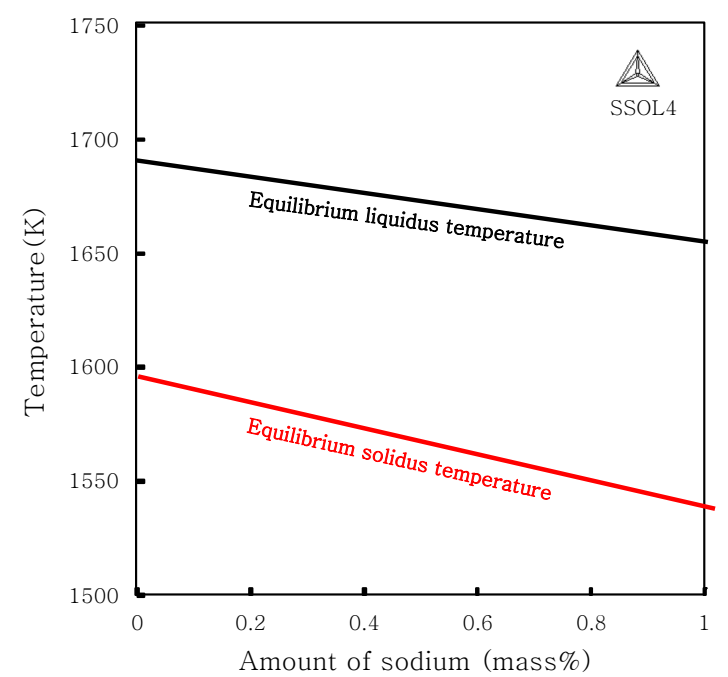

Fig. 13 Calculation result of the relationship between the amount of sodium added to type 316FR stainless steel and the temperature range of solid/liquid coexistence, as determined from the Thermo-calc software (database: SSOL4)

\section{Conclusions}

The effect of a metallic sodium environment on the solidification cracking susceptibility (BTR) was quantitatively evaluated via a transverse-Varestraint test. The main conclusions of this study can be summarized as follows:

1) The solidification mode of type 316FR stainless steel weld metal was characterized by primary $\gamma$ with secondary phase $\delta$ solidification (AF) mode with divorced-eutectic reaction between the two phases; the $\delta$ phase constituted an average volume fraction of $3 \%$.

2) A BTR of $37 \mathrm{~K}$ was determined from the transverse- Varestraint test of the steel weld metal.

3) The BTR expanded from 37 to $67 \mathrm{~K}$ with an increase, from 0 to $7.99 \mathrm{mg} / \mathrm{cm}^{2}$, in the amount of adhered metallic sodium. In other words, the solidification cracking susceptibility of type 316FR stainless steel weld metal increased in the metallic sodium environment.

4) Sodium has the ability to mix with the weld metal, thereby forming a mixing zone in the sub-surface region of the weld metal and forms an oxide with alloying elements in the bulk of the metal. This observation suggested that sodium acts as an impurity during the welding solidification.

5) As determined by thermodynamics software, the temperature range of solid/liquid coexistence in the equilibrium state expanded from 92.2 to $117.2 \mathrm{~K}$ with an increase (from 0 to 1 mass $\%$ ) in the amount of sodium added to the steel.

6) Calculation of the temperature range of the sol$\mathrm{id} /$ liquid coexistence in the equilibrium state revealed the mechanism of the BTR expansion in the residual sodium environment; this expansion, which was attributed to the segregation of sodium during the welding solidification, resulted in an expanded BTR.

\section{Acknowledgment}

The present study includes the results of the "Core $R \& D$ program for commercialization of the fast breeder reactor by utilizing Monju" entrusted to the University of Fukui by the Ministry of Education, Culture, Sports, Science, and Technology of Japan (MEXT).

\section{References}

1. T. Nakazawa et al., Advanced Type Stainless Steel 316FR for Fast Breeder Reactor Structures, Journal of Materials Processing Technology, 143-144 (20) (2003), 905-909

2. K. Aoto, Remodeling of Coolant System, Development 
of SUS316 FBR Grade and Its Application to "JOYO" MK-III Intermediate Heat Exchanger, JNC Technical Review, 21 (12) (2003), 63-75 (in Japanese)

3. A. Maruyama et al., Journal of the Atomic Energy Society of Japan, 26 (4) (1984), 327-338 (in Japanese)

4. T. Furukawa et al., Effect of Sodium Environment on Creep and Fatigur Properties of FBR Grade Type 316 Stainless Steel, Journal of Society of Materials Science, Japan, 48 (12) (1999), 1373-1378 (in Japanese)

5. W. F. Savage and C. D. Lundin, Welding Journal, 44(10) (1965), 433s-442s

6. J. C. Lippold and D. J. Kotecki, Welding Metallurgy and Weldability of Stainless Steels, A John Wiley \& Sons, New York (2005), 141-229

7. S. Kou, Welding metallurgy, 2nd ed., A John Wiley \& Sons, New York (2003), 216-242

8. V. M. Radhakrishnan, Hot Cracking in Austenitic Stainless Steel Weld Metal, Science and Technology of Welding and Joining, 5 (1) (2000), 40-44

9. Y. Arata et al., Varestrant Test for Solidification Cracking Susceptibility in Weld Metal of Austenitic Stainless Steel, Transactions of JWRI, 3 (1) (1974), 79-88

10. F. Matsuda et al., Fractographic Investigation on Solidification Crack in the Varestraint Test of Fully Austenitic Stainless Steel, Transactions of JWRI, 7 (1) (1978), 59-70

11. F. Matsuda et al., The VDR Cracking Test for Solidification Crack Susceptibility on Weld Metals and Its Application to Aluminium Alloys, Transactions of JWRI, 8 (1) (1979), $85-95$

12. T. Ogawa and E. Tsunetomi, Hot Cracking Susceptibility of Austenitic Stainless Steels, Welding Journal, 61 (3) (1982), 82s-93s

13. J. C. Lippold and W. F. Savage, Solidification of Austenitic Stainless Steel Weldments (Part 3)-The Effect of Solidification Behavior on Hot Cracking Susceptibility-, Welding Journal, 61 (12) (1982), 388s- 396s

14. F. Matsuda et al., Quantitative Evaluation of Solidification Brittleness of Weld Metal during Solidification by means of In-situ Observation and Measurement (Report 1)-Development of the MISO Technique-, Transactions of JWRI 12 (1) (1983), 65-72

15. F. Matsuda et al., Solidification Crack Susceptibility in Laser Beam Weld Metal of 0.2C Low Alloy Steels-Effect of Bead Configuration and S and P Contents-, Transactions of JWRI, 16 (2) (1987), 103-114
16. J. C. Lippold, Solidification Behavior and Cracking Susceptibility of Pulsed-laser Welds in Austenitic Stainless Steel, Welding Journal, 73 (6) (1994), 129s-139s

17. S. Katayama, Solidification Phenomena of Weld MetalsSolidification Cracking Mechanism and Cracking Susceptibility (3rd Report)-, Welding International, 15 (8) (2001), 627-636

18. K. Saida et al., Contribution of Phosphorus and Sulfur on Hot Cracking Susceptibility of Extra-high-purity-25Cr35Ni Stainless Steels, Welding Journal, 92 (11) (2013), 322s-331s

19. K. Saida et al., Quantitative Influence of Minor and Impurity Elements of Solidification Cracking Susceptibility of Extra High Purity Type 310 Stainless Steel, Science and Technology of Welding and Joining, 18 (7) (2013), 616623

20. E. J. Chun et al., Solidification Cracking Behavior in Austenitic Stainless Steel Laser Welds (Part 1)-Evaluation of Solidification Cracking Susceptibility by Laser Beam Welding Varestraint Test-, J. of Welding and Joining, 34 (5) (2016), 54-60 (in Korean)

21. 21. E. J. Chun et al., Solidification Cracking Behavior in Austenitic Stainless Steel Laser Welds (Part 2)-Effects of $\delta$-ferrite Crystallization and Solidification Segregation Behavior on Solidification Cracking Susceptibility-, J. of Welding and Joining, 34 (5) (2016), 61-69 (in Korean)

22. H. Inoue et al., Solidification and Transformation Behavior of Austenitic Stainless Steel Weld Metals Solidified as Primary Austenite-Study of Solidification and Subsequent Transformation of Cr-Ni Stainless Steel Weld Metals (1st Report)-, Welding International, 11 (11) (1997), 876-887

23. H. Inoue et al., Solidification and Transformation Behavior of Austenitic Stainless Steel Weld Metals Solidified as Primary Ferrite-Study of Solidification and Subsequent Transformation of Cr-Ni Stainless Steel Weld Metals (2nd Report)-, Welding International, 11 (12) (1997), 937949

24. T. Hashimoto et al., Metallurgical Evaluation for Residual Stress Measurement Accuracy of Multi-Pass Girth Welded Pipe Joint in Austenitic Stainless Steel by X-Ray Diffraction, Journal of the Japan Society for Testing Materials, 60 (7) (2011), 610-616 (in Japanese)

25. J. Huang et al., Assessment of Thermochemical Data of Ternary Na-Fe Oxides and Calculation of Na-Fe-O Phase Diagram, JNC TN9400 2002- 006 (2002) (in Japanese) 